\title{
Substituted 4-Acyl-5-methyl-2-phenyl-pyrazol-3-one- phenylhydrazones with Antioxidant Properties: X-Ray Crystal and Spectroscopic Studies
}

\author{
Omoruyi G. Idemudia, ${ }^{1}$ Anthony I. Okoh, ${ }^{2}$ Alexander P. Sadimenko, ${ }^{1}$ \\ Eric C. Hosten, ${ }^{3}$ and Omobola O. Okoh ${ }^{1}$ \\ ${ }^{1}$ Chemistry Department, University of Fort Hare, Private Bag x1314, Alice 5700, South Africa \\ ${ }^{2}$ SAMRC, Microbial Water Quality Monitoring Centre, University of Fort Hare, Alice 5700, South Africa \\ ${ }^{3}$ Chemistry Department, Nelson Mandela Metropolitan University, P.O. Box 77000, Port Elizabeth 6031, South Africa \\ Correspondence should be addressed to Omoruyi G. Idemudia; oidemudia@ufh.ac.za
}

Received 26 June 2017; Revised 19 September 2017; Accepted 12 October 2017; Published 13 November 2017

Academic Editor: Davut Avci

Copyright (C) 2017 Omoruyi G. Idemudia et al. This is an open access article distributed under the Creative Commons Attribution License, which permits unrestricted use, distribution, and reproduction in any medium, provided the original work is properly cited.

Phenylhydrazine was reacted with synthesized acylpyrazolone derivatives 4-ethyl-5-methyl-2-phenyl-pyrazol-3-one and 4-propyl5-methyl-2-phenyl-pyrazol-3-one, to obtain two new azomethine phenylhydrazones, a study in continuation of our probe into the effects of acyl group substitutions on the physicochemical and free radical scavenging properties of acylpyrazolone Schiff bases. The keto imine tautomers of 4-ethyl-5-methyl-2-phenyl-pyrazol-3-one-phenylhydrazone (Empp- $\mathrm{Ph}$ ) and 4-propyl-5-methyl-2phenyl-pyrazol-3-one-phenylhydrazone (Prmpp-Ph) according to single X-ray crystallography data which precipitated in good yield are reported. Furthermore they have been characterized by elemental analysis, FTIR, ${ }^{13} \mathrm{C}$ and ${ }^{1} \mathrm{H}$ NMR, and mass-spectroscopy techniques. Both phenylhydrazone Schiff bases crystallize in a triclinic crystal system, each with a space group of P-1 (number 2) having short intramolecular $\mathrm{N} 3-\mathrm{H} 3$...O1 hydrogen interaction between the first hydrazine hydrogen $\mathrm{H} 3$ and the pyrazolone oxygen O1. The antioxidant free radical scavenging activities of titled compounds against 2,2-diphenyl-1-picrylhydrazyl (DPPH) showed a positive response almost as good as that of vitamin $\mathrm{c}$ under the same conditions, with the propyl substituted 4-propyl-5methyl-2-phenyl-pyrazol-3-one-phenylhydrazone (Prmpp-Ph) having a stronger activity (calculated $\mathrm{IC}_{50}$ value of $175.66 \mu \mathrm{g} / \mathrm{ml}$ ).

\section{Introduction}

The synthesis of new compounds with unique properties has continued to be one of the scientific approaches employed by coordination chemists towards the search for alternative therapeutic agents to address the problems of medicinal drugs toxicity effects and disease resistance [13]. Similarly, these compounds mostly organic/inorganic based, as ligands or/and their metal complexes, are obtained through careful functional groups modifications by way of formulation, which invariably affects their properties and influence specific applications [4-6]. Acylpyrazolone derivatives, mostly known for their use as analytical reagents in the extraction and separation of various metal ions, made possible because of their chelating properties, are a group of bidentate diketones that have been well researched [7-10].
They are important precursors in the synthesis of a more superior group of acylpyrazolone Schiff bases, obtained by their reaction with amines in a condensation process [11]. Since its discovery, Schiff bases in the midst of its numerous applications have been receiving profound research interest because of its pharmacological properties, a characteristic that is attributed to the azomethine $\mathrm{C}=\mathrm{N}$ functional group that it possesses $[2,12,13]$. The available lone pair electrons in $\mathrm{sp}^{2}$ hybridized orbital of the $\mathrm{C}=\mathrm{N}$ nitrogen atom interfere with the normal cell membrane by forming hydrogen bonds with these active centers of cell constituents to inhibit its growth.

Schiff bases either in its form or as coordination metal complexes have gained research interest as free radical scavenging agents (antioxidant properties) [14]. Free radicals are highly unstable atoms, molecules, or ions having 
unpaired electrons which are derived from oxygen, nitrogen, or sulfur, forming reactive oxygen species (ROS), reactive nitrogen species (RNS), and reactive sulfur species (RSS), respectively. The oxidative properties impact of these free radicals present within the human metabolic system has been of great concern as it is revealed to be the leading cause of most life endangering ailments [15]; as such the need for a closer look at understanding their origin and modes of action amongst other characteristics, which will in turn give room for strategic approach in scavenging them, is most important. Tridentate 3-formyl chromone Schiff bases showed good antioxidant activities against DPPH at different concentrations with as low as $1.27 \mathrm{~g} / \mathrm{ml} \mathrm{IC}_{50}$ value compared to standard drug BHT $\left(\mathrm{IC}_{50}\right.$ value of $0.67 \mathrm{~g} / \mathrm{ml}$ ) [16]. More recently, Karthik and fellow researchers synthesized a series of Schiff bases with 4-(methylthio)benzaldehydes that have shown to highly scavenge free radicals [17]. Acylpyrazolone Schiff bases synthesized from the condensation reaction of some acylpyrazolone derivatives with sulfanilamide that showed antioxidant properties have been reported by our group [18]. Latest on our findings was the synthesis of new stable Schiff bases with dinitrophenylhydrazine having interesting structural hydrogen bonding and spectroscopic characteristics [2]. In this paper however, it is revealed that ethyl and propyl substitution on acylpyrazolone Schiff bases greatly influence their free radical scavenging behavior, and these results were carefully attained from a study of the antioxidant activities of these new phenylhydrazones, starting with synthesis and followed by their characterization as well as structural elucidation.

\section{Experimental}

2.1. Materials, Physical Measurements, and Methods. 3Methyl-1-phenyl-2-pyrazolin-5-one, propionyl chloride, and butyryl chloride were purchased from Sigma Aldrich and used as received for the synthesis of the 4-acylpyrazolone precursors. Phenylhydrazine and other reagents/solvents of standard analytical grade were obtained from the same supplier. ${ }^{1} \mathrm{H}$ and ${ }^{13} \mathrm{C}$ NMR spectra were recorded in deuterated DMSO on a Varian Unity Inova 600 NMR spectrometer with a ${ }^{1} \mathrm{H}$ frequency of $600 \mathrm{MHz}$ and a ${ }^{13} \mathrm{C}$ frequency of $150 \mathrm{MHz}$ using trimethylsilane TMS as internal standard. Spectra data were collected in a $5 \mathrm{~mm}$ dual channel IDpfg probe and chemical shifts were expressed in $\operatorname{ppm}(\delta$ scale). The Mestrenova 9.0 software package was used for processing of NMR spectra. Mass spectra were analyzed with atmosphericpressure chemical ionization (APCI) method using a direct insertion probe (DIP) on the Bruker micrOTOF-Q II 10390 mass spectrometer. An external calibration with sodium formate was performed to attain the correct accurate mass. FTIR spectroscopy was measured within the range of $4000-370 \mathrm{~cm}^{-1}$ on the new PerkinElmer Spectrum Two FTIR UATR Spectroscopy with the spectrum 10.5.3 software used for spectra preparation. The uncorrected melting point was determined using the GallenKamp melting point apparatus and the LECO.TRUSpec Micro CHNS analyzer was employed for the elemental analyses of synthesized ligands. Single crystal X-ray diffraction studies were performed at $200 \mathrm{~K}$ using a Bruker Kappa Apex II diffractometer with graphite monochromated Mo K $\alpha$ radiation $(\lambda=0.71073 \AA)$.

\subsection{Synthesis of Phenylhydrazones}

2.2.1. 4-Ethyl-5-methyl-2-phenyl-pyrazol-3-one-phenylhydrazone Empp-Ph. A mixture of 4-ethyl-5-methyl-2-phenylpyrazol-3-one Empp ( $2 \mathrm{mmol}, 0.46 \mathrm{~g}$ ) in methanol $(40 \mathrm{~mL})$ and a solution of phenylhydrazine $(2.0 \mathrm{mmol}, 0.22 \mathrm{~g})$ in methanol $(20 \mathrm{~mL})$ was stirred under reflux for 6 hours. The obtained solution with a yellow solid was filtered and the product precipitate was washed with methanol, followed by a small amount of diethyl ether. The yellow crystalline solid was recrystallized in methanol, dried at room temperature, and stored over fused calcium chloride in a desiccator. Yield: 79\%. Mol. Wt.: $320.38 \mathrm{~g} / \mathrm{mol} .{ }^{1} \mathrm{H}$ NMR (DMSO- $d_{6}$, $600 \mathrm{MHz}), \delta(\mathrm{ppm}) 12.24(\mathrm{~s}, 1 \mathrm{H}), 8.52(\mathrm{~s}, 1 \mathrm{H}), 8.02-7.97(\mathrm{~m}$, $2 \mathrm{H}), 7.38(\mathrm{dd}, J=8.6,7.3 \mathrm{~Hz}, 2 \mathrm{H}), 7.28(\mathrm{dd}, J=8.6,7.3 \mathrm{~Hz}$ $2 \mathrm{H}), 7.15-7.09(\mathrm{~m}, 1 \mathrm{H}), 6.90(\mathrm{t}, J=7.3 \mathrm{~Hz}, 1 \mathrm{H}), 6.86-6.81(\mathrm{~m}$, $2 \mathrm{H}), 2.82(\mathrm{q}, J=7.6 \mathrm{~Hz}, 2 \mathrm{H}), 2.37(\mathrm{~s}, 3 \mathrm{H}), 1.24(\mathrm{t}, J=7.6 \mathrm{~Hz}$, 3H). ${ }^{13} \mathrm{C}$ NMR $(600 \mathrm{MHz}, \mathrm{DMSO}): \delta(\mathrm{ppm})=172.7(\mathrm{~s}$, $\mathrm{C}=\mathrm{O}), 165.5(\mathrm{~s}, \mathrm{C}=\mathrm{N}), 147.4-112.7$ ( $\mathrm{m}$, aromatic carbons), 96.2 (s, pyrazolone $\mathrm{CH}_{3}$ ), 16.3 (s, acyl $\mathrm{CH}_{2}-\mathrm{CH}_{3}$ ), 12.8 (s, acyl $\mathrm{CH}_{2}-\mathrm{CH}_{3}$ ). M.p.: $161-163^{\circ} \mathrm{C}$. Elemental analysis Calc. for $\mathrm{C}_{19} \mathrm{H}_{20} \mathrm{~N}_{4} \mathrm{O}$ : C 71.23\%; H 6.29\%; N 17.49\%. Found: C 71.50\%; $\mathrm{H} 5.98 \% ; \mathrm{N} 17.46 \%$. IR $v_{\max }\left(\mathrm{cm}^{-1}\right): v(\mathrm{~N}-\mathrm{H}): 3295, v(\mathrm{C}-\mathrm{H})$ : 2975, $v(\mathrm{C}=\mathrm{N}): 1616, v(\mathrm{C}=\mathrm{O}): 1534, v(\mathrm{C}-\mathrm{O}): 1382, v(\mathrm{C}-\mathrm{N})$ : 1063. APCI-MS: $m / z 321.17\left([\mathrm{M}+\mathrm{H}]^{+}, 100 \%\right)$.

2.2.2. 4-Propyl-5-methyl-2-phenyl-pyrazol-3-one-phenylhydrazone Prmpp-Ph. A mixture of propyl-5-methyl-2-phenylpyrazol-3-one Prmpp (2 mmol, $0.49 \mathrm{~g})$ in methanol $(40 \mathrm{~mL})$ and a solution of phenylhydrazine $(2.0 \mathrm{mmol}, 0.22 \mathrm{~g})$ in methanol $(20 \mathrm{~mL})$ was stirred under reflux for 6 hours. The obtained solution with a yellow solid was filtered and the product precipitate was washed with methanol, followed by a small amount of diethyl ether. The yellow crystalline solid was recrystallized in methanol, dried at room temperature, and stored over fused calcium chloride in a desiccator. Yield: 72\%. Mol. Wt.: $334.41 \mathrm{~g} / \mathrm{mol}^{1}{ }^{1} \mathrm{H}$ NMR (600 MHz, DMSO- $d_{6}$ ) $\delta 12.30(\mathrm{~s}, 1 \mathrm{H}), 8.50(\mathrm{~s}, 1 \mathrm{H}), 8.03-7.98(\mathrm{~m}, 2 \mathrm{H}), 7.38(\mathrm{dd}, J=$ 8.6, $7.3 \mathrm{~Hz}, 2 \mathrm{H}), 7.27$ (t, $J=7.7 \mathrm{~Hz}, 2 \mathrm{H}), 7.12(\mathrm{t}, J=7.4 \mathrm{~Hz} 1 \mathrm{H})$, $6.90(\mathrm{t}, J=7.3 \mathrm{~Hz}, 1 \mathrm{H}), 6.83(\mathrm{~d}, J=8.0 \mathrm{~Hz}, 2 \mathrm{H}), 2.81-2.75(\mathrm{~m}$, 2H), 2.37 (s, 3H), 1.65 (q, $J=7.8 \mathrm{~Hz}, 2 \mathrm{H}), 1.00(\mathrm{t}, J=7.4 \mathrm{~Hz}$, $3 \mathrm{H}) .{ }^{13} \mathrm{C}$ NMR $(600 \mathrm{MHz}, \mathrm{DMSO}): \delta(\mathrm{ppm})=171.3(\mathrm{~s}, \mathrm{C}=\mathrm{O})$, $165.5(\mathrm{~s}, \mathrm{C}=\mathrm{N}), 147.4-112.9(\mathrm{~m}$, aromatic carbons), $96.6(\mathrm{~s}$, pyrazolone $\mathrm{CH}_{3}$ ), 21.9 (s, acyl $\mathrm{CH}_{2}-\mathrm{CH}_{2}-\mathrm{CH}_{3}$ ), 16.4 (s, acyl $\mathrm{CH}_{2}-\mathrm{CH}_{3}$ ), 14.0 (s, acyl $\mathrm{CH}_{2}-\mathrm{CH}_{2}-\mathrm{CH}_{3}$ ). M.p.: $172-174^{\circ} \mathrm{C}$. Elemental analysis Calc. for $\mathrm{C}_{20} \mathrm{H}_{22} \mathrm{~N}_{4} \mathrm{O}$ : C 71.83\%; $\mathrm{H}$ 6.63\%; N 16.75\%. Found: C 71.75\%; H 6.20\%; N 16.69\%. IR $v_{\max }\left(\mathrm{cm}^{-1}\right): v(\mathrm{~N}-\mathrm{H}): 3299, v(\mathrm{C}-\mathrm{H}): 2965, v(\mathrm{C}=\mathrm{N}): 1613, v$ $(\mathrm{C}=\mathrm{O}): 1582, v(\mathrm{C}-\mathrm{O}): 1378, v(\mathrm{C}-\mathrm{N}): 1075$. APCI-MS: $\mathrm{m} / z$ $335.19\left([\mathrm{M}+\mathrm{H}]^{+}, 100 \%\right)$.

2.2.3. X-Ray Diffraction Studies of Empp-Ph and Prmpp-Ph. Single crystal X-ray diffraction analyses were performed at $200 \mathrm{~K}$ using a Bruker Kappa Apex II diffractometer with 
monochromated Mo $\mathrm{K} \alpha$ radiation $(\lambda=0.71073 \AA$ ). APEX2 [19] was used for data collection and SAINT [20] for cell refinement and data reduction. The structures were solved by direct methods using SHELXS-2013 [21] and refined by least-squares procedures using SHELXL-2013 [21] with SHELXLE [22] as a graphical interface. Data were corrected for absorption effects using the numerical method implemented in SADABS [20]. All nonhydrogen atoms were refined anisotropically. Carbon-bound $\mathrm{H}$ atoms were placed in calculated positions ( $\mathrm{C}-\mathrm{H}$ bond lengths of $0.95 \AA$ for aromatic carbon atoms; $0.99 \AA$ for methylene) and were included in the refinement in the riding model approximation, with $U_{\text {iso }}(\mathrm{H})$ set to $1.2 U_{\text {eq }}(\mathrm{C})$. The $\mathrm{H}$ atoms of the methyl groups were allowed to rotate with a fixed angle around the $\mathrm{C}-\mathrm{C}$ bond to best fit the experimental electron density (HFIX 137 in the SHELX program suite $[21,23])$ with $U_{\text {iso }}(H)$ set to $1.5 U_{\text {eq }}(\mathrm{C})$ and $\mathrm{C}-\mathrm{H}$ bond lengths of $0.98 \AA$. The nitrogenbound $\mathrm{H}$ atoms were located on a different Fourier map and refined freely.

2.2.4. Antioxidant (Free Radical Scavenging) Activity. The free radical scavenging potentials of reported ligands were carefully tested against the free radicals of 2,2-diphenyl-2picrylhydrazyl (DPPH), according to the method employed earlier but with up to date modifications [18]. Test compounds were prepared in a mixture of DMF and methanol with mole ratio of $1: 9$, respectively, for different concentrations (100, $200,300,400$, and $500 \mu \mathrm{g} / \mathrm{mL}$ ). $1 \mathrm{~mL}$ solution of $0.4 \mathrm{mmol}$ $\mathrm{DPPH}$ in methanol was added to $3 \mathrm{~mL}$ prepared solutions of test compounds. The same procedure was carried out for vitamin $\mathrm{C}$ as standard/reference drug. Methanolic DPPH without test sample as control and an equal volume of dissolving solvents which did not show any effect on DPPH were also recorded. The set-up was shaken vigorously and allowed to stand at room temperature in the dark for about $30 \mathrm{~min}$. The absorbance of each test sample mixture was measured with a UV-Vis spectrophotometer at a constant wavelength of $517 \mathrm{~nm}$. The percentage scavenging capabilities of synthesized compounds were calculated using the expression

$$
\text { Scavenging activity }(\%)=\frac{A_{0}-A_{1}}{A_{0}} \times 100 \text {, }
$$

where $A_{0}$ is the absorbance of control sample and $A_{1}$ is the absorbance of test samples including that of standard drug. The $\mathrm{IC}_{50}$ value, which is the concentration of each test sample required to scavenge 50 percent of the free radicals of DPPH, was calculated using the $R^{2}$ linear regression formulae $y=m x$ $+c$, obtained from the plot of percentage scavenging activity against concentration of test samples. The smaller the $\mathrm{IC}_{50}$ value the greater the potency of the test compound.

\section{Results and Discussion}

3.1. Synthesis, Physical Properties, and Elemental Analysis. The general synthesis scheme for the reported phenylhydrazones is shown in Figure 1. Air stable, nonhygroscopic ligands were precipitated in high yield from the condensation reaction of previously synthesized ethyl and propyl acylpyrazolone derivatives with phenylhydrazine in a simple onepot synthesis set-up. They were recrystallized from methanol and with slow evaporation of their dry samples in ethanol solution; single crystals suitable for X-ray crystallography were grown.

Obtained elemental analysis data were in agreement with calculated percentage composition of $\mathrm{CHN}$ values. The titled compounds were generally soluble in basic organic solvents with short range melting point presented in the experimental section.

3.2. ${ }^{1} \mathrm{H}$ and ${ }^{13} \mathrm{C}$ NMR Spectroscopy. ${ }^{1} \mathrm{H}$ and ${ }^{13} \mathrm{C}$ NMR spectroscopy data have been used to verify both the hydrogen and carbon environments of the structures of reported phenylhydrazones as obtained from single crystal X-ray crystallography. The ${ }^{1} \mathrm{H}$ NMR signals associated with aromatic protons $(\mathrm{ArH})$ resonated at a downfield region between 8.52 and $6.83 \mathrm{ppm}$ in the NMR spectra of ligands [18], with an integration values of 11 protons each. A singlet each resonating at $12.24 \mathrm{ppm}$ in Empp-Ph and at $12.30 \mathrm{ppm}$ in Prmpp-Ph further downfield is due to the protonation of the azomethine nitrogen $\mathbf{H N}=\mathrm{C}$, Figure 2. Signals due to alkyl group protons resonate at an upfield region of 2.82, 2.37, and 1.24 ppm in Empp-Ph and at 2.75, 2.37, 1.65, and 1.00 ppm in Prmpp-Ph.

In the ${ }^{13} \mathrm{C}$ NMR spectra of synthesized compounds, Figure 3, carbon atoms due to keto $\mathrm{C}=\mathrm{O}$ and azomethine $\mathrm{C}=\mathrm{N}$ groups display resonance signals at 165.5 and $147.4 \mathrm{ppm}$ in Empp-Ph and Prmpp-Ph, respectively [24]. Also the signals due to aromatic carbon are observed as multiplets and resonate in the chemical shift range of 147.4 and $112.9 \mathrm{ppm}$. The substituted aliphatic carbon environment resonates as singlets in the chemical shift region between 21.9 and $12.8 \mathrm{ppm}$.

3.3. Mass-Spectroscopy. The APCI-mass spectra with molecular ion peak intensities of $100 \%$ are observed for Empp$\mathrm{Ph}$ and Prmpp-Ph having molecular ion values of 321.17 and $335.19 \mathrm{~m} / z$, respectively, equivalent to a protonation of the ligands $[\mathrm{M}+\mathrm{H}]^{+}$(Figure 4). Also, in the mass-spectrum of Empp-Ph, the peak with $\mathrm{m} / z$ at 641.33 corresponds to the molecular weight of 2 molecules of Empp-Ph, which may be due to the formation of a dimer. However the molecular ions observed are in close agreement with calculated theoretical molecular weight plus a proton [2].

3.4. Infrared Spectroscopy. IR spectra of ligands have been carefully obtained using their pure powder samples on the new PerkinElmer Spectrum Two FTIR UATR Spectroscopy and the spectra were processed using the spectrum 10.5.3 software. Strong bands due to azomethine $v(\mathrm{C}=\mathrm{N})$ and keto $v(\mathrm{C}=\mathrm{O})$ at 1616 and $1534 \mathrm{~cm}^{-1}$, respectively, peculiar with acylpyrazolone Schiff bases are observed in the IR spectrum of Empp-Ph which were in agreement with obtained crystal structure. These frequency vibrations are observed in PrmppPh at $1613 \mathrm{~cm}^{-1}$ for $v(\mathrm{C}=\mathrm{N})$ and $1582 \mathrm{~cm}^{-1}$ for $v(\mathrm{C}=\mathrm{O})$ which is consistent with previous findings [23]. Further, vibration 


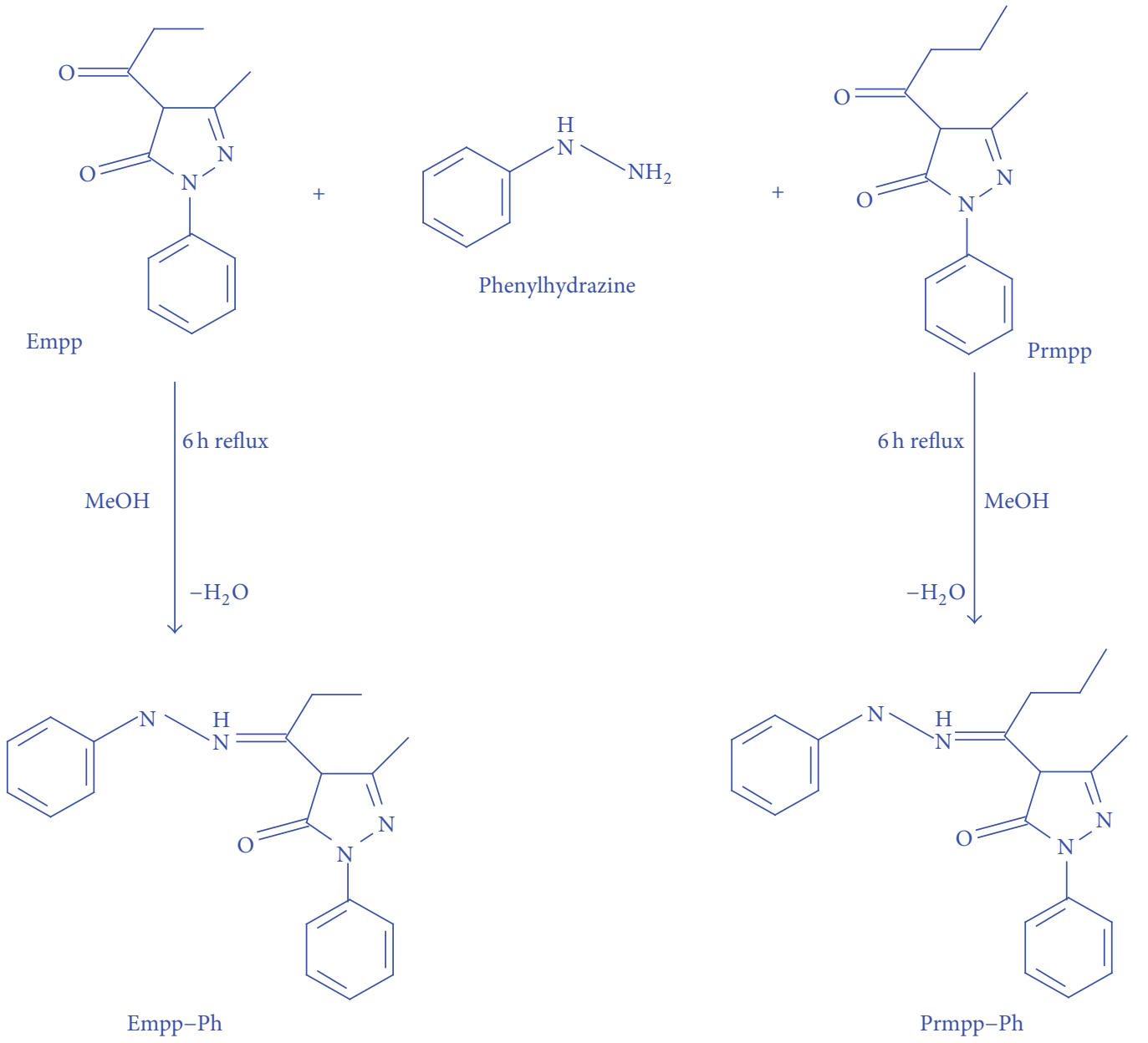

FIGURE 1: Synthesis of 4-acyl-5-methyl-2-phenyl-pyrazol-3-one-phenylhydrazones.

peaks observed as medium bands at 3295 and $2975 \mathrm{~cm}^{-1}$ in Empp-Ph due to $v(\mathrm{~N}-\mathrm{H})$ and $v(\mathrm{C}-\mathrm{H})$, respectively, vibrate at 3299 and $2965 \mathrm{~cm}^{-1}$ in the IR spectrum of Prmpp-Ph. In addition to the confirmation of the successful synthesis of reported acylpyrazolone phenylhydrazones, the IR spectra have displayed relevant functional group vibrations at appropriate wave numbers $\mathrm{cm}^{-1}$ as presented in the experimental section.

3.5. X-Ray Crystallography. Single crystal structures of synthesized phenylhydrazone derivatives were obtained from a slow evaporation of their ethanol solution. Crystal data summary are presented in Table 1.

The structure of reported compounds, 4-ethyl-5-methyl2-phenyl-pyrazol-3-one-phenylhydrazone Empp-Ph and 4propyl-5-methyl-2-phenyl-pyrazol-3-one-phenylhydrazone Prmpp-Ph, is similar to previously described 4-phenyl-5methyl-2-phenyl-pyrazol-3-one-phenylhydrazone Pmpp-Ph [25]. Structures Empp-Ph and Prmpp-Ph (Figure 5) are isostructural in the P-1 space group, while structure Pmpp$\mathrm{Ph}$ has the $\mathrm{P} 21 / \mathrm{c}$ space group.

The methyl-pyrazolone-hydrazine cores are essentially planar with RMS deviation of fitted atoms of 0.0281 for
Empp-Ph, 0.0285 for Prmpp-Ph, and 0.0493 for Pmpp$\mathrm{Ph}$ indicating that the phenyl group in $\mathrm{Pmpp}-\mathrm{Ph}$ exhibits greater steric hindrance [25]. Core planarity is also aided by a short intramolecular $\mathrm{N} 3-\mathrm{H} 3 . . \mathrm{O} 1$ hydrogen interaction between the first hydrazine hydrogen $\mathrm{H} 3$ and the pyrazalone oxygen O1 with interaction lengths of 1.935(14) for Empp$\mathrm{Ph}, 1.928$ (16) for Prmpp-Ph, and 1.994(18) $\AA$ for Pmpp-Ph. In terms of graph-set analysis $[19,26]$ the descriptor is $S_{1}{ }^{1}(6)$ on the unary level.

The phenyl groups bonded to the pyrazalone groups are turned slightly out of the methyl-pyrazolone-hydrazine core planes by $21.43(5)^{\circ}$ for Empp-Ph, 21.21(6) for Prmpp-Ph, and 12.15(6) $)^{\circ}$ for Pmpp-Ph. Each structure has an intramolecular $\mathrm{C} 12-\mathrm{H} 12$...O1 interaction which can be described by a $\mathrm{S}_{1}{ }^{1}$ (6) descriptor on the unary level and limits the rotation of the phenyl group. The bond lengths are 2.35, 2.45, and $2.26 \AA$ for Empp-Ph, Prmpp-Ph, and Pmpp- $\mathrm{Ph}$, respectively.

In contrast the phenyl groups bonded to the hydrazine are all almost perpendicular to the core plane by $88.46^{\circ}$ for Empp-Ph, $89.24^{\circ}$ for Prmpp-Ph, and $85.34^{\circ}$ for Pmpp-Ph. The phenyl hydrazine group is held in place by two $\mathrm{C}-\mathrm{H} . \ldots \pi$ ring interactions: one with a phenyl (C11-C16) ring and the other with a pyrazole (N1 N2 C1 C2 C3) ring with hydrogen 
196_H1

${ }^{1} \mathrm{H}$ NMR $\left(600 \mathrm{MHz}\right.$, DMSO- $\left.d_{6}\right) \delta 12.24(\mathrm{~s}, 1 \mathrm{H}), 8.52(\mathrm{~s}, 1 \mathrm{H}), 8.02-7.97(\mathrm{~m}, 2 \mathrm{H}), 7.38(\mathrm{dd}, J=8.6,7.3$

$\mathrm{Hz}, 2 \mathrm{H}), 7.28(\mathrm{dd}, J=8.6,7.3 \mathrm{~Hz}, 2 \mathrm{H}), 7.15-7.09(\mathrm{~m}, 1 \mathrm{H}), 6.90(\mathrm{t}, J=7.3 \mathrm{~Hz}, 1 \mathrm{H}), 6.86-6.81(\mathrm{~m}, 2 \mathrm{H})$, $2.82(\mathrm{q}, J=7.6 \mathrm{~Hz}, 2 \mathrm{H}), 2.37(\mathrm{~s}, 3 \mathrm{H}), 1.24(\mathrm{t}, J=7.6 \mathrm{~Hz}, 3 \mathrm{H})$.
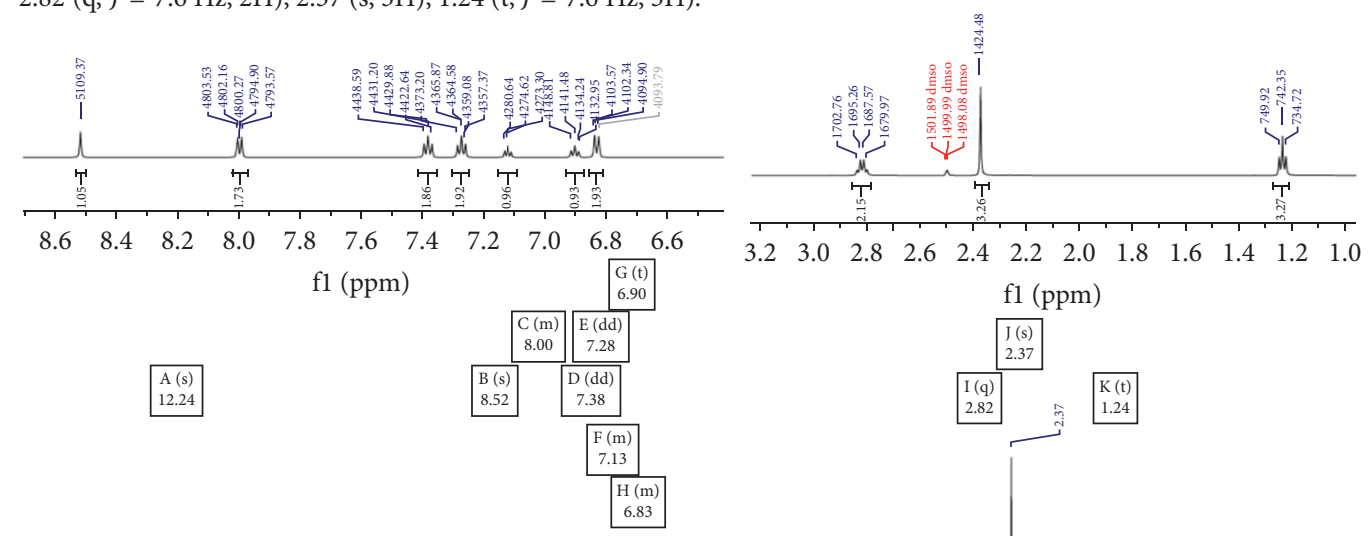

f1 (ppm)
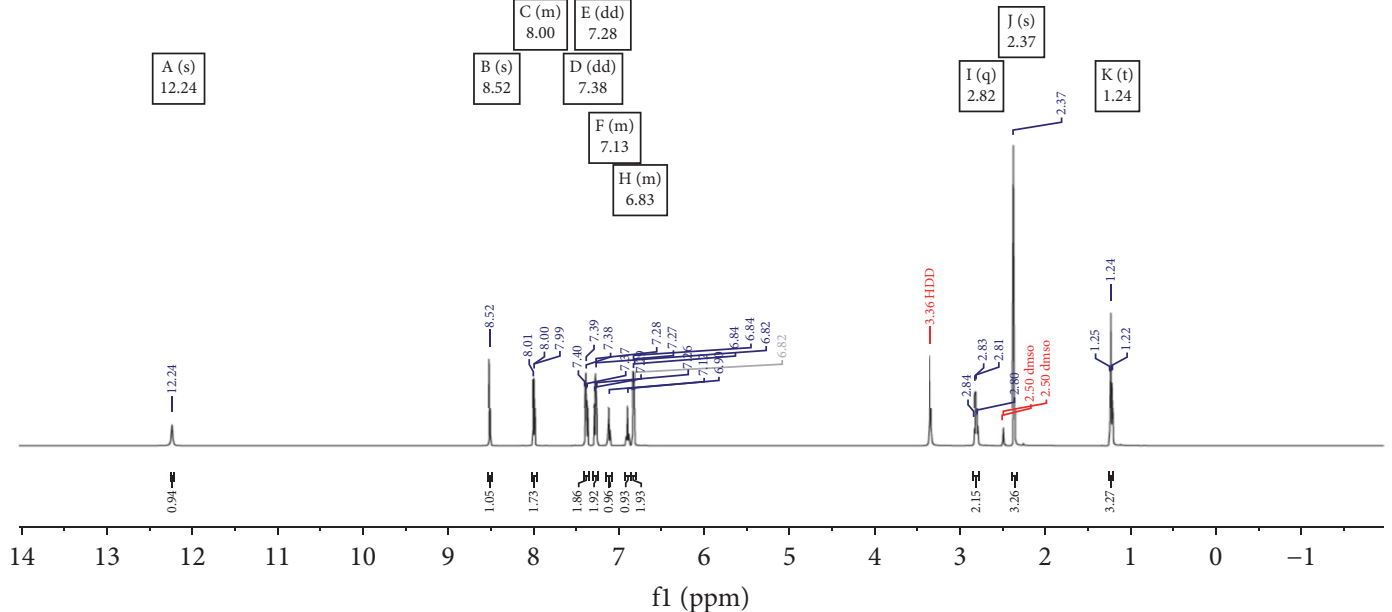

(a)

190_H1

${ }^{1} \mathrm{H}$ NMR $\left(600 \mathrm{MHz}\right.$, DMSO- $\left.d_{6}\right) \delta 12.30(\mathrm{~s}, 1 \mathrm{H}), 8.50(\mathrm{~s}, 1 \mathrm{H}), 8.03-7.98(\mathrm{~m}, 2 \mathrm{H}), 7.38(\mathrm{dd}, J=8.6,7.3$

$\mathrm{Hz}, 2 \mathrm{H}), 7.27(\mathrm{t}, J=7.7 \mathrm{~Hz}, 2 \mathrm{H}), 7.12(\mathrm{t}, J=7.4 \mathrm{~Hz}, 1 \mathrm{H}), 6.90(\mathrm{t}, J=7.3 \mathrm{~Hz}, 1 \mathrm{H}), 6.83(\mathrm{~d}, J=8.0 \mathrm{~Hz}$,

$2 \mathrm{H}), 2.81-2.75(\mathrm{~m}, 2 \mathrm{H}), 2.37(\mathrm{~s}, 3 \mathrm{H}), 1.65(\mathrm{q}, J=7.8 \mathrm{~Hz}, 2 \mathrm{H}), 1.00(\mathrm{t}, J=7.4 \mathrm{~Hz}, 3 \mathrm{H})$
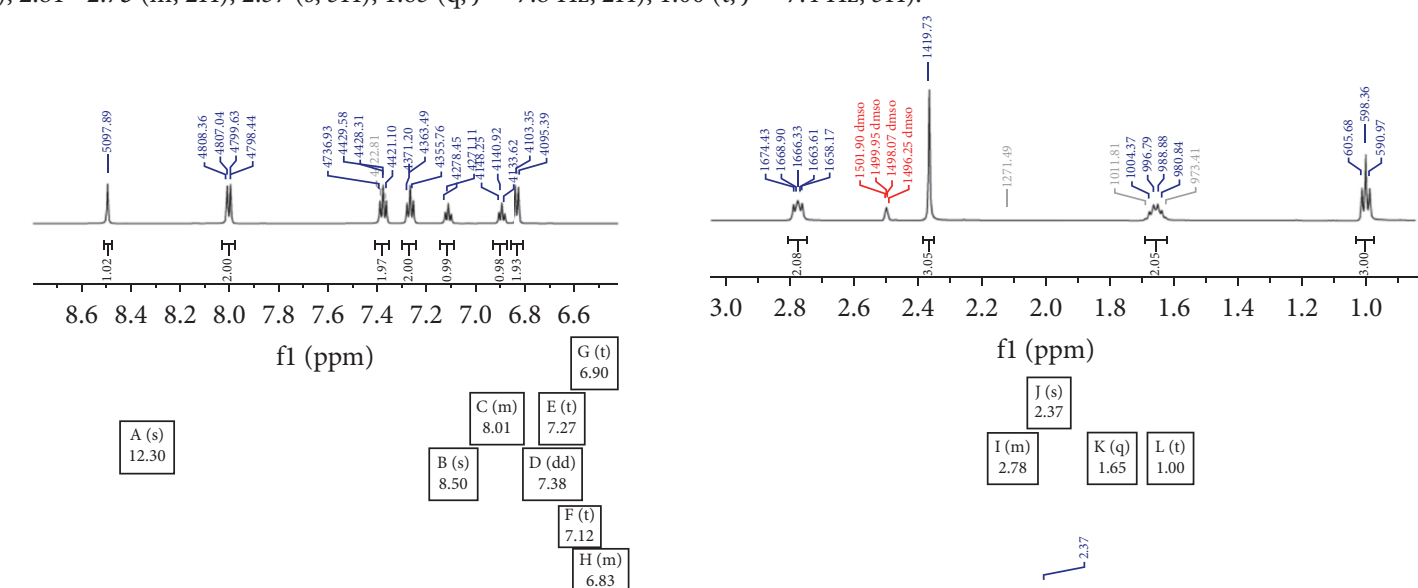

\begin{tabular}{c|c}
$\mathrm{G}(\mathrm{t})$ \\
6.90
\end{tabular}

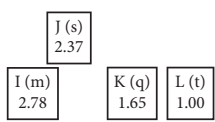

(m)

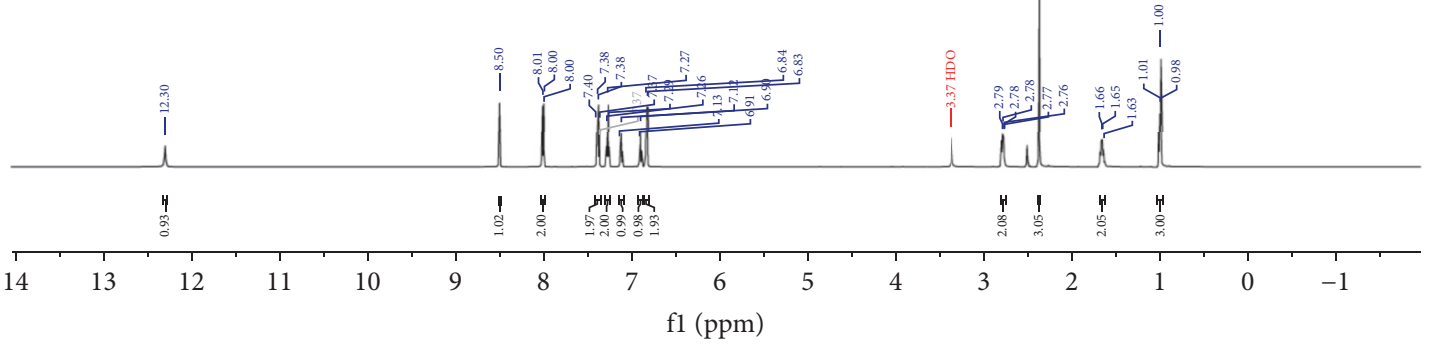

(b)

Figure 2: (a) ${ }^{1} \mathrm{H}$ NMR spectrum of Empp-Ph; (b) ${ }^{1} \mathrm{H}$ NMR spectrum of Prmpp-Ph. 

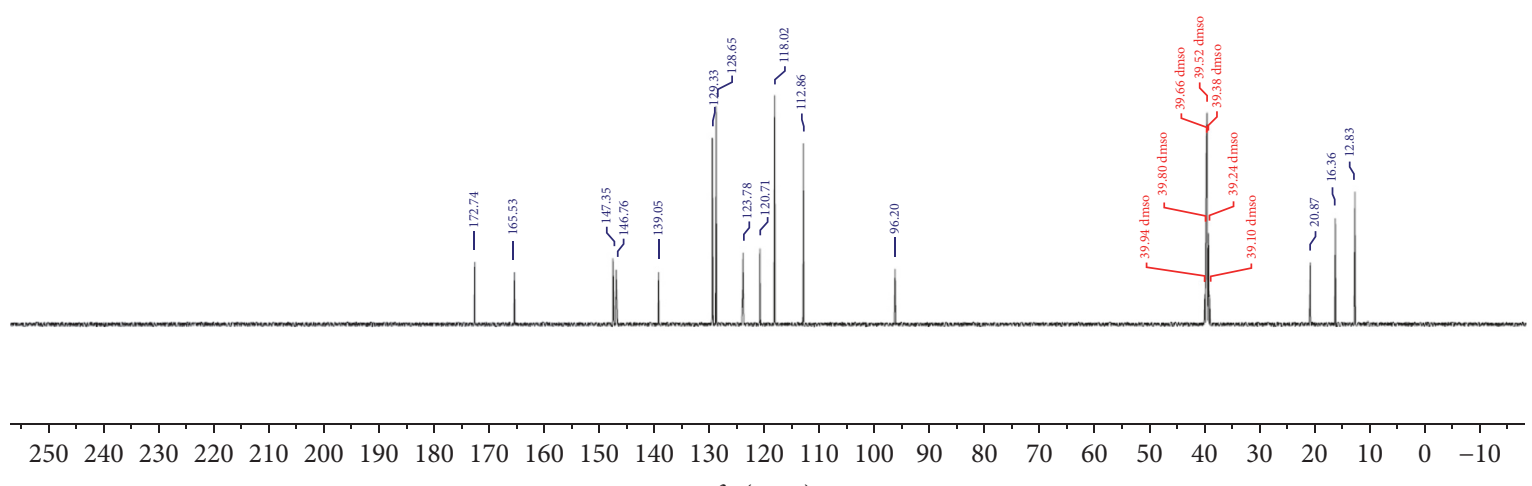

f1 (ppm)

(a)

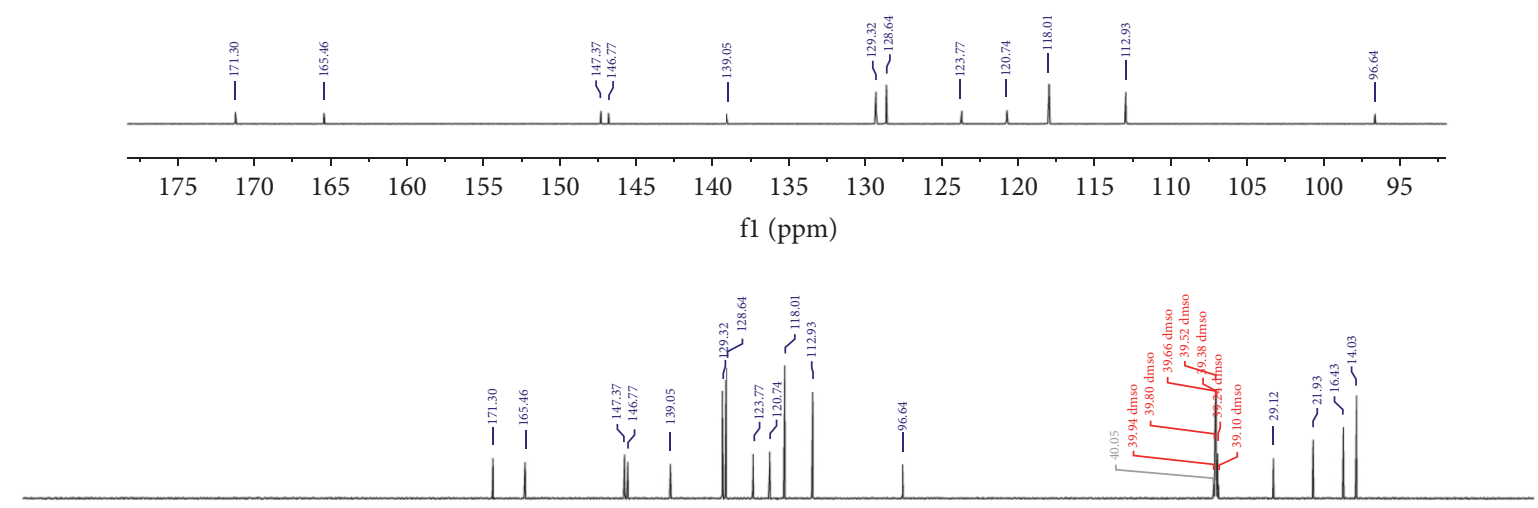

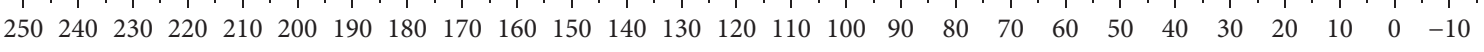

f1 (ppm)

(b)

Figure 3: (a) ${ }^{13} \mathrm{C}$ NMR spectrum of Empp-Ph; (b) ${ }^{13} \mathrm{C}$ NMR spectrum of Prmpp-Ph.

to centroid distances of 2.84 and $2.65 \AA$, respectively, Figure 6 . The hydrogen bonding and parking diagrams of Prmpp-Ph are not presented as they have the same structural behavior and crystal orientation as Empp-Ph.

Between two adjacent molecules in structures Empp-Ph and Prmpp-Ph, there are two N4-H4...O1 intermolecular hydrogen bonds which can be described with a $R_{2}{ }^{2}(14)$ descriptor on the unary level. The bond lengths are 2.321(15) for Empp-Ph and 2.368(16) for Prmpp-Ph. For structure Pmpp-Ph the second hydrazine hydrogen $\mathrm{H} 4$ is not involved with a hydrogen bond, but instead between two adjacent molecules where there are two intermolecular $\mathrm{N} 4-\mathrm{H} 4$. . . $\pi$ ring interactions of 2.728(17) $\AA$ to phenyl groups bonded to the pyrazalones.

3.6. Antioxidant Studies against DPPH. The extent to which synthesized Schiff bases can scavenge free radicals of DPPH was carefully carried out in vitro in triplicate and the average of absorbance values of test samples at different concentrations was measured at a constant wavelength of
$517 \mathrm{~nm}$. Interesting antioxidant activities have been exhibited by the reported phenylhydrazones compared to the standard drug, vitamin C. A progressive increase in the percentage antioxidant activity with increasing concentration of test compounds as depicted in Table 2 and Figure 7 was recorded [17]. Based on the calculated $\mathrm{IC}_{50}$ values, Prmpp-Ph has shown a stronger antioxidant property overall, with an $\mathrm{IC}_{50}$ value of $175.66 \mu \mathrm{g} / \mathrm{ml}$ followed by Empp-Ph with an $\mathrm{IC}_{50}$ of $193.90 \mu \mathrm{g} / \mathrm{ml}$. It is understood that Prmpp-Ph showed a stronger scavenging potential because of the presence of more electron donating hydrogen environment giving room for the ease of releasing protons responsible for free radical reduction.

\section{Conclusions}

New substituted acylpyrazolone phenylhydrazones with excellent antioxidant properties relative to standard drug vitamin $\mathrm{C}$ have been identified based on their abilities to scavenge free radicals of DPPH. The propyl phenylhydrazone 


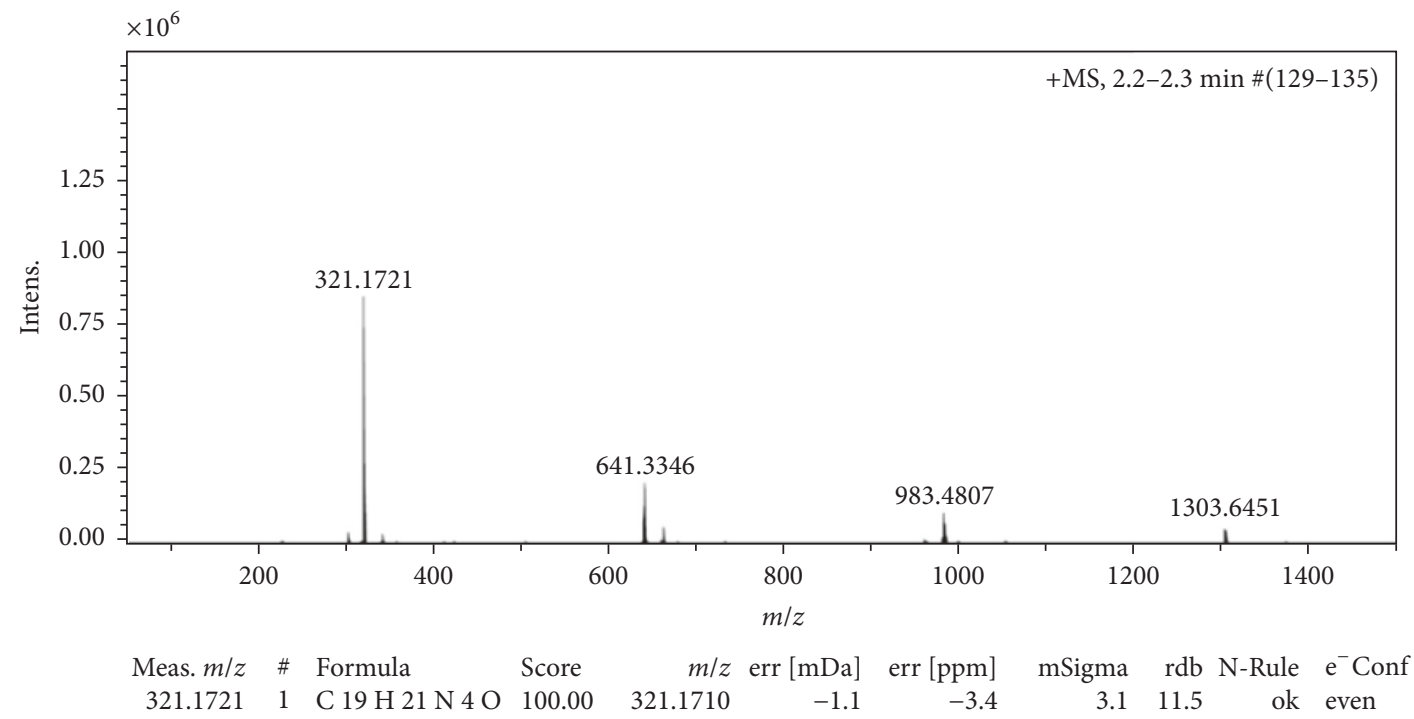

(a)

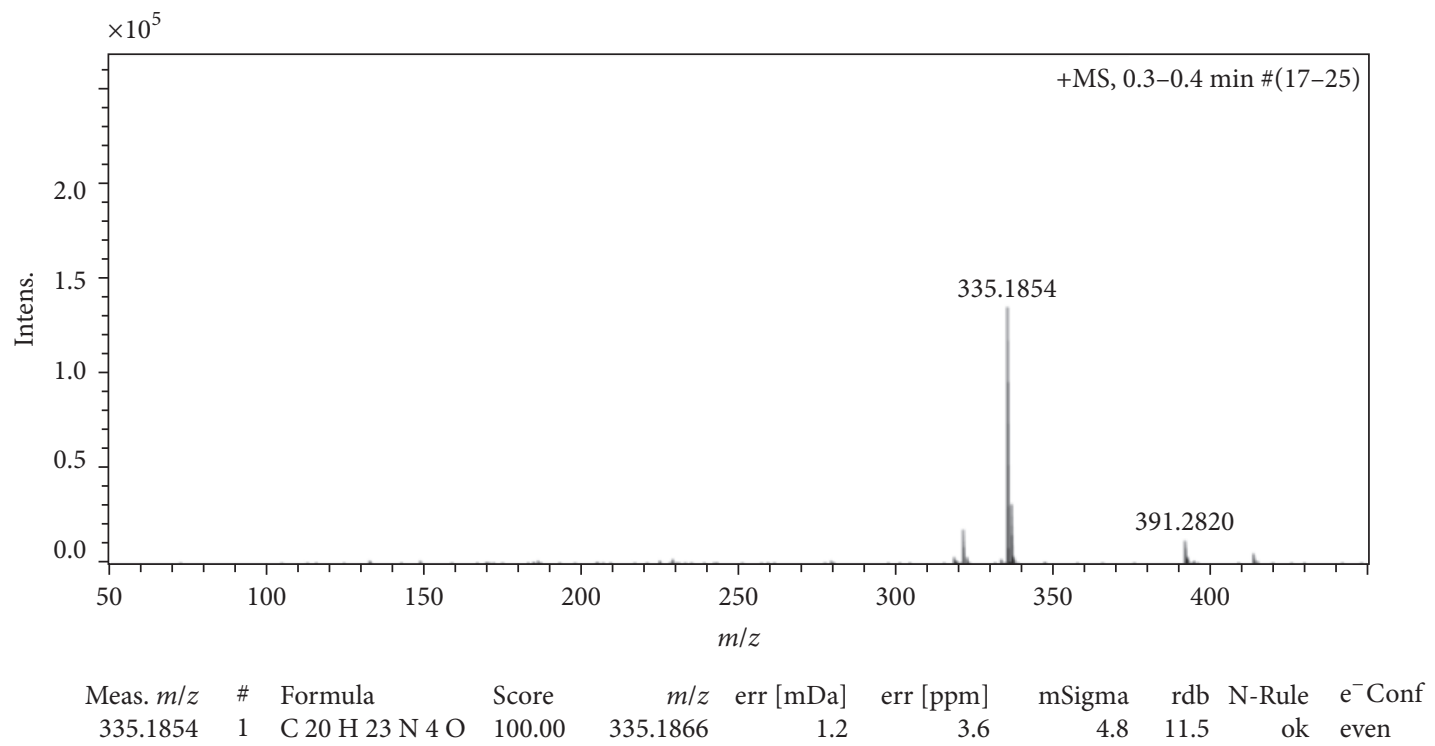

(b)

Figure 4: (a) Mass-spectrum of Empp-Ph; (b) mass-spectrum of Prmpp-Ph.

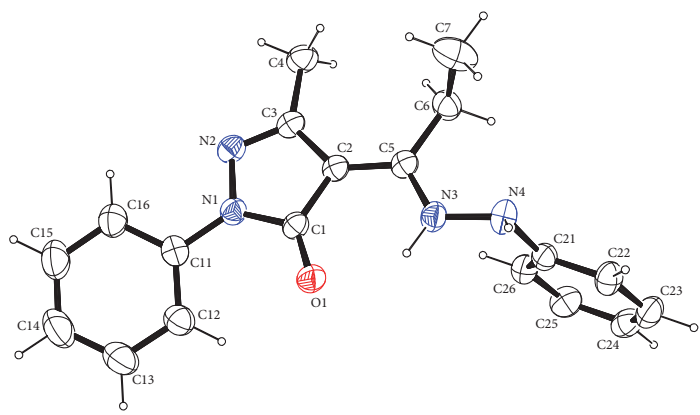

(a)

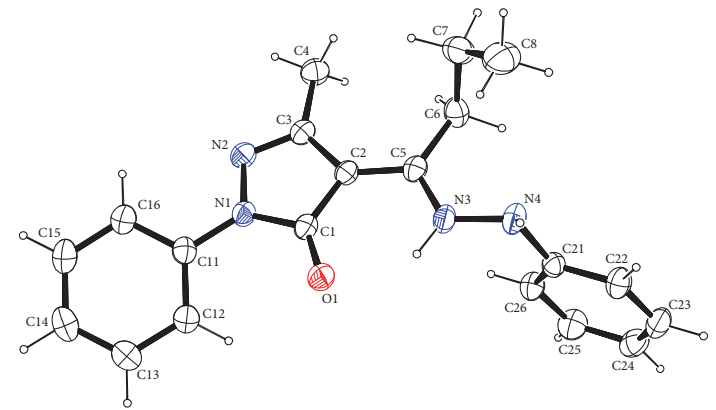

(b)

Figure 5: Ortep diagrams of (a) Empp-Ph single crystal and (b) Prmpp-Ph single crystal with ellipsoids, drawn at 50\% probability level. 


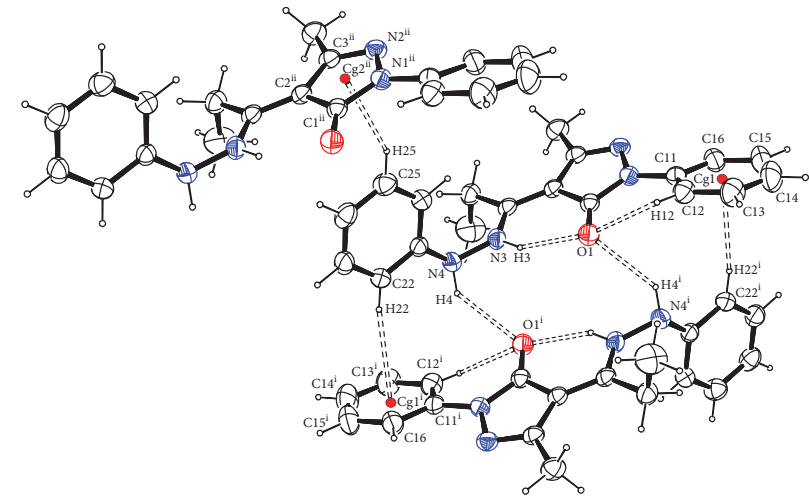

(a)

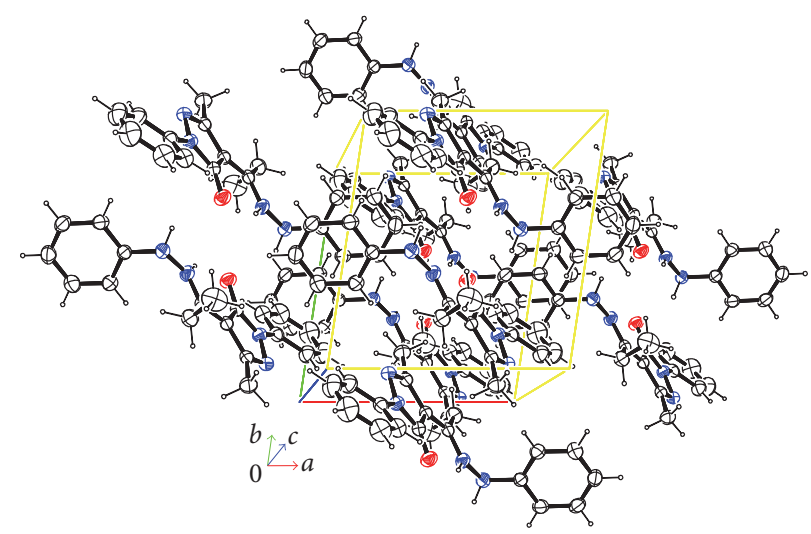

(b)

FIGURE 6: Hydrogen bonding and parking diagrams of Empp-Ph. Ellipsoids drawn at 50\% probability level: (a) hydrogen interactions for Empp-Ph. Cg1 and Cg2 are the centroids for the phenyl ring C11-C16 and the pyrazole ring N1 N2 C1 C2 C3, respectively. Symmetry operations: (i) $1-x, 1-y,-z$; (ii) $-1+x, y$, z. (b) Packing diagram of Empp-Ph viewed normal to (001).

TABle 1: Crystallographic data for Empp-Ph and Prmpp-Ph.

\begin{tabular}{|c|c|c|c|}
\hline Compound & Empp-Ph & Prmpp-Ph & Pmpp-Ph [25] \\
\hline Formula & $\mathrm{C}_{19} \mathrm{H}_{20} \mathrm{~N}_{4} \mathrm{O}$ & $\mathrm{C}_{20} \mathrm{H}_{22} \mathrm{~N}_{4} \mathrm{O}$ & $\mathrm{C}_{23} \mathrm{H}_{20} \mathrm{~N}_{4} \mathrm{O}$ \\
\hline Crystal colour and form & Yellow/block & Golden yellow/block & Yellow/block \\
\hline Formula weight & 320.39 & 334.42 & 368.43 \\
\hline Crystal system & Triclinic & Triclinic & Monoclinic \\
\hline Space group & P-1 & P-1 & $\mathrm{P} 21 / \mathrm{c}$ \\
\hline$a$ & $8.8820(2)(\AA)$ & $9.0474(3)(\AA)$ & $8.6806(2)(\AA)$ \\
\hline$b$ & 9.5593(3) (§̊) & $9.4350(3)(\AA)$ & $20.4319(4)(\AA)$ \\
\hline$c$ & $10.4678(3)(\AA)$ & $10.5546(3)(\AA)$ & $10.6100(2)(\AA)$ \\
\hline$\alpha$ & $80.690(1)^{\circ}$ & $81.162(1)^{\circ}$ & $90^{\circ}$ \\
\hline$\beta$ & $81.658(1)^{\circ}$ & $78.850(1)^{\circ}$ & $99.713(1)^{\circ}$ \\
\hline$\gamma$ & $81.484(1)^{\circ}$ & $82.568(2)^{\circ}$ & $90^{\circ}$ \\
\hline V & $860.69(4)\left(\AA^{3}\right)$ & $868.84(5)\left(\AA^{3}\right)$ & $1854.83(7)\left(\AA^{3}\right)$ \\
\hline$Z$ & 2 & 2 & 4 \\
\hline$D_{(\text {calc })}$ & $1.236\left(\mathrm{Mg} \mathrm{cm}^{-1}\right)$ & $1.278\left(\mathrm{Mg} \mathrm{cm}^{-1}\right)$ & $1.319\left(\mathrm{Mg} \mathrm{cm}^{-1}\right)$ \\
\hline$F(000)$ & 340 & 356 & 776 \\
\hline$\theta$ range & $2.2,28.3\left(^{\circ}\right)$ & $2.0,28.4\left(^{\circ}\right)$ & $2.4,28.3\left(^{\circ}\right)$ \\
\hline Crystal size & $0.25 \times 0.33 \times 0.40(\mathrm{~mm})$ & $0.31 \times 0.32 \times 0.47(\mathrm{~mm})$ & $0.33 \times 0.40 \times 0.45(\mathrm{~mm})$ \\
\hline Dataset & $-11: 11 ;-12: 12 ;-13: 13$ & $-12: 11 ;-12: 12 ;-14: 14$ & $-11: 11 ;-27: 26 ;-14: 14$ \\
\hline Tot., uniq. data, R(int) & $19169,4275,0.014$ & $15195,4294,0.019$ & $17965,4607,0.014$ \\
\hline Observed data $[I>2 \sigma(I)]$ & 3705 & 3632 & 3891 \\
\hline Temperature & $200(\mathrm{~K})$ & $200(\mathrm{~K})$ & $200(\mathrm{~K})$ \\
\hline Parameters & 227 & 237 & 262 \\
\hline $\mathrm{w} R 2, \mathrm{~S}$ & $0.1035,1.05$ & $0.1027,1.04$ & $0.1079,1.04$ \\
\hline
\end{tabular}

TABLE 2: Antioxidant scavenging activity data of Empp-Ph and Prmpp-Ph (\%).

\begin{tabular}{|c|c|c|c|c|c|c|c|}
\hline \multirow{2}{*}{ Test compounds } & \multicolumn{5}{|c|}{ Percentage antioxidant activity \% } & \multirow{2}{*}{$\mathrm{IC}_{50} \mu \mathrm{g} / \mathrm{ml}$} & \multirow{2}{*}{$R^{2}$} \\
\hline & $100 \mu \mathrm{g} / \mathrm{ml}$ & $200 \mu \mathrm{g} / \mathrm{ml}$ & $300 \mu \mathrm{g} / \mathrm{ml}$ & $400 \mu \mathrm{g} / \mathrm{ml}$ & $500 \mu \mathrm{g} / \mathrm{ml}$ & & \\
\hline Empp-Ph & 0.29 & 31.65 & 79.52 & 80.36 & 82.00 & 193.90 & 0.82 \\
\hline Prmpp-Ph & 3.61 & 16.15 & 77.78 & 77.87 & 78.8 & 175.66 & 0.79 \\
\hline Vit. C & 0.26 & 10.71 & 34.22 & 84.51 & 82.67 & 87.54 & 0.91 \\
\hline
\end{tabular}




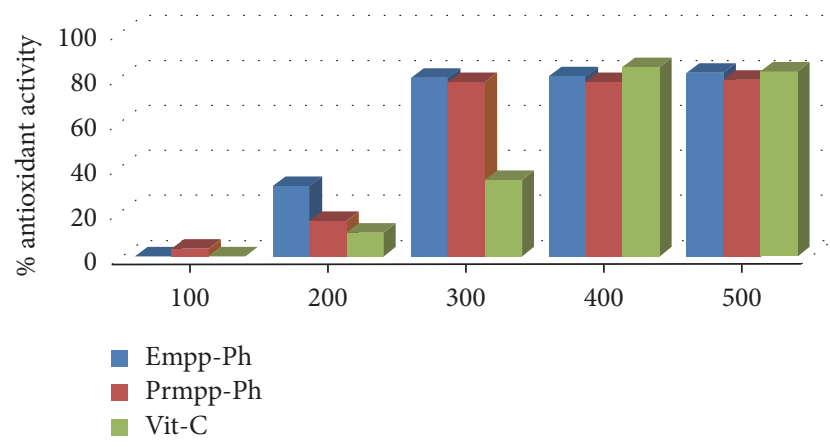

FIGURE 7: Chart showing the antioxidant activities of acylpyrazolone phenylhydrazones.

derivative Prmmp-Ph showed a stronger antioxidant activity which has been attributed to the presence of more hydrogen atoms that can be released in a process of deprotonation to scavenge free radical. Spectroscopic techniques data has corroborated their single crystal X-ray structures. In addition, their good hydrogen bonding properties according to X-ray crystallography studies could be a factor of their stability and as such they may become a significant contribution to the pull of synthesized compounds that may qualify as clinical trials for potential anticancer candidates.

\section{Conflicts of Interest}

The authors declare that there are no conflicts of interest regarding the publication of this paper.

\section{Acknowledgments}

The financial support of the South Africa Medical Research Council and the University of Fort Hare is appreciated.

\section{References}

[1] J. Palmucci, F. Marchetti, R. Pettinari et al., "Synthesis, structure, and anticancer activity of arene-ruthenium(II) complexes with acylpyrazolones bearing aliphatic groups in the acyl moiety," Inorganic Chemistry, vol. 55, no. 22, pp. 11770-11781, 2016.

[2] O. G. Idemudia and E. C. Hosten, "Spectroscopy, crystal and molecular structures of new 4-acylpyrazolone dinitrophenylhydrazones," Crystals, vol. 6, no. 127, pp. 1-10, 2016.

[3] Y. J. Mange, A. M. Isloor, S. Malladi, S. Isloor, and H.-K. Fun, "Synthesis and antimicrobial activities of some novel 1,2,4triazole derivatives," Arabian Journal of Chemistry, vol. 6, no. 2, pp. 177-181, 2013.

[4] R. Yang, Y. G. Liu, K. Van Hecke, and G. H. Cui, "Synthesis and characterization of two cobalt(II) coordination polymers based on 5-tert-butyl isophthalic acid and bis(benzimidazole) ligands," Transition Metal Chemistry, vol. 40, no. 3, pp. 333-340, 2015.

[5] W. H. Mahmoud, R. G. Deghadi, and G. G. Mohamed, "Novel Schiff base ligand and its metal complexes with some transition elements. synthesis, spectroscopic, thermal analysis, antimicrobial and in vitro anticancer activity," Applied Organometallic Chemistry, vol. 30, no. 4, pp. 221-230, 2016.
[6] H.-Q. Chang, L. Jia, J. Xu et al., "Syntheses, crystal structures, anticancer activities of three reduce Schiff base ligand based transition metal complexes," Journal of Molecular Structure, vol. 1106, pp. 366-372, 2016.

[7] S. Parihar, S. K. Gupta, R. N. Jadeja, and P. K. Jha, "A comparative study of experimental and theoretical results of conformations of oxovanadium(IV) complexes with 4-acyl pyrazolone ligands using DFT method," Spectrochimica Acta Part A: Molecular and Biomolecular Spectroscopy, vol. 128, pp. 447-451, 2014.

[8] F. Marchetti, C. Pettinari, and R. Pettinari, "Acylpyrazolone ligands: synthesis, structures, metal coordination chemistry and applications," Coordination Chemistry Reviews, vol. 249, no. 24, pp. 2909-2945, 2005.

[9] O. G. Idemudia, A. P. Sadimenko, and E. C. Hosten, "Crystal structure of bis(4-benzoyl-3-methyl-1-phenyl pyrazol-5-one)bis(N,N-dimethylformamide)cobalt(II), $\quad \mathrm{C}_{40} \mathrm{H}_{40} \mathrm{CoN}_{6} \mathrm{O}_{6}$," Zeitschrift fur Kristallographie - New Crystal Structures, vol. 230, no. 2, pp. 83-84, 2015.

[10] F. Marchetti, R. Pettinari, and C. Pettinari, "Recent advances in acylpyrazolone metal complexes and their potential applications," Coordination Chemistry Reviews, vol. 303, pp. 1-31, 2015.

[11] O. G. Idemudia, A. P. Sadimenko, and E. C. Hosten, "Crystal structure of 4-benzoyl-3-methyl-1-phenyl-2-pyrazolin-5-one sulfadiazine dimethylformamide monosolvate, $\mathrm{C}_{30} \mathrm{H}_{29} \mathrm{~N}_{7} \mathrm{O}_{4} \mathrm{~S}$," Zeitschrift fur Kristallographie - New Crystal Structures, vol. 229, no. 4, pp. 455-457, 2014.

[12] L. P. Singh and J. M. Bhatnagar, "Copper(II) selective electrochemical sensor based on Schiff Base complexes," Talanta, vol. 64, no. 2, pp. 313-319, 2004.

[13] R. N. Jadeja, S. Parihar, K. Vyas, and V. K. Gupta, "Synthesis and crystal structure of a series of pyrazolone based Schiff base ligands and DNA binding studies of their copper complexes," Journal of Molecular Structure, vol. 1013, pp. 86-94, 2012.

[14] W. Al Zoubi, A. A. S. Al-Hamdani, and M. Kaseem, "Synthesis and antioxidant activities of Schiff bases and their complexes: a review," Applied Organometallic Chemistry, vol. 30, no. 10, pp. 810-817, 2016.

[15] M. Carocho and I. C. F. R. Ferreira, "A review on antioxidants, prooxidants and related controversy: natural and synthetic compounds, screening and analysis methodologies and future perspectives," Food and Chemical Toxicology, vol. 51, no. 1, pp. 15-25, 2013.

[16] P. Kavitha, M. Saritha, and K. Laxma Reddy, "Synthesis, structural characterization, fluorescence, antimicrobial, antioxidant and DNA cleavage studies of $\mathrm{Cu}(\mathrm{II})$ complexes of formyl chromone Schiff bases," Spectrochimica Acta Part A: Molecular and Biomolecular Spectroscopy, vol. 102, pp. 159-168, 2013.

[17] C. S. Karthik, L. Mallesha, S. Nagashree, P. Mallu, V. Patil, and S. Kumar, "Schiff bases of 4-(methylthio)benzaldehydes: synthesis,characterization, antibacterial, antioxidant and cytotoxicity Studies," Current Chemistry Letters, pp. 71-82, 2016.

[18] O. G. Idemudia, A. P. Sadimenko, A. J. Afolayan, and E. C. Hosten, "Synthesis and Characterization of Bioactive Acylpyrazolone Sulfanilamides and Their Transition Metal Complexes: Single Crystal Structure of 4-Benzoyl-3-methyl-1-phenyl-2pyrazolin-5-one Sulfanilamide," Bioinorganic Chemistry and Applications, vol. 2015, Article ID 717089, 23 pages, 2015.

[19] M. C. Etter, J. C. MacDonald, and J. Bernstein, "Graph-set analysis of hydrogen-bond patterns in organic crystals," Acta Crystallographica Section B: Structural Science, vol. 46, no. 2, pp. 256-262, 1990. 
[20] "Bruker. “APEX2, SAINT, SADABS," Bruker AXS Inc., Madison, Wis, USA, 2007".

[21] G. M. Sheldrick, "Crystal structure refinement with SHELXL," Acta Crystallographica Section C, vol. 71, pp. 3-8, 2015.

[22] C. B. Hübschle, G. M. Sheldrick, and B. Dittrich, "ShelXle: a Qt graphical user interface for SHELXL," Journal of Applied Crystallography, vol. 44, no. 6, pp. 1281-1284, 2011.

[23] O. G. Idemudia, A. P. Sadimenko, and E. C. Hosten, "Metal complexes of new bioactive pyrazolone phenylhydrazones; crystal structure of 4-acetyl-3-methyl-1-phenyl-2-pyrazoline5-one phenylhydrazone ampp-ph," International Journal of Molecular Sciences, vol. 17, no. 5, article no. 687, pp. 1-24, 2016.

[24] W. Hernández, J. Paz, F. Carrasco et al., "Synthesis and characterization of New Palladium(II) thiosemicarbazone complexes and their cytotoxic activity against various human tumor cell lines," Bioinorganic Chemistry and Applications, vol. 2013, Article ID 524701, 12 pages, 2013.

[25] O. G. Idemudia, A. P. Sadimenko, A. J. Afolayan, and E. C. Hosten, "3-Methyl-1-phenyl-4-[(phenyl)(2-phenyl-hydrazin-1yl)methylidene] -1H-pyrazol-5(4H)-one," Acta Crystallographica Section E: Structure Reports Online, vol. 68, no. 5, pp. 12801281, 2012.

[26] J. Bernstein, R. E. Davies, L. Shimoni, and N.-L. Chang, "Patterns in hydrogen bonding: functionality and graph set analysis in crystals," Angewandte Chemie, vol. 34, no. 15, pp. 1555-1573, 1995. 

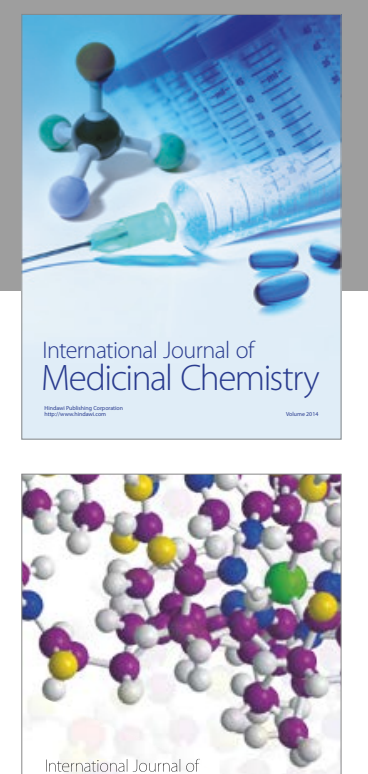

Carbohydrate Chemistry

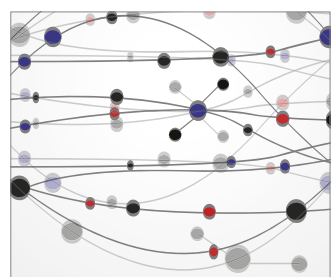

The Scientific World Journal
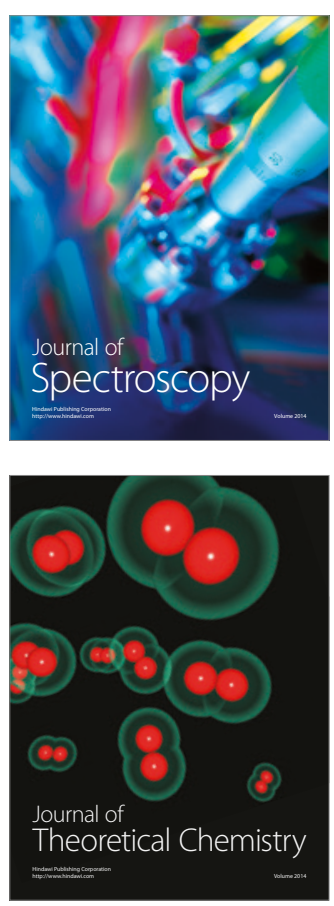
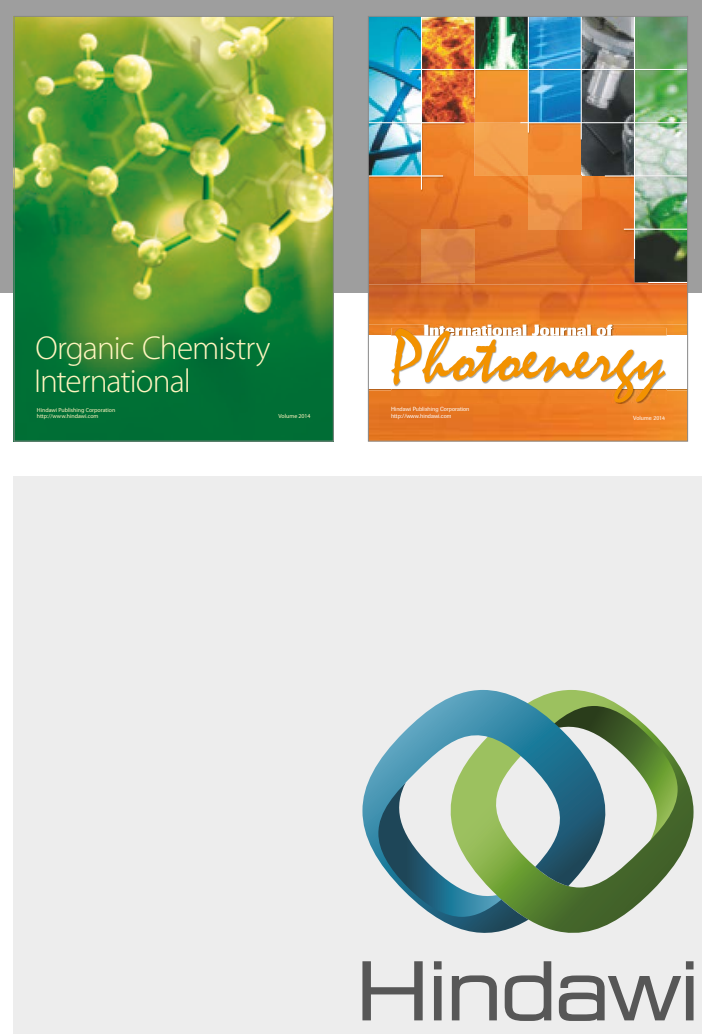

Submit your manuscripts at

https://www.hindawi.com

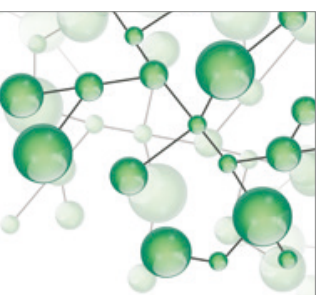

International Journal of

Inorganic Chemistry

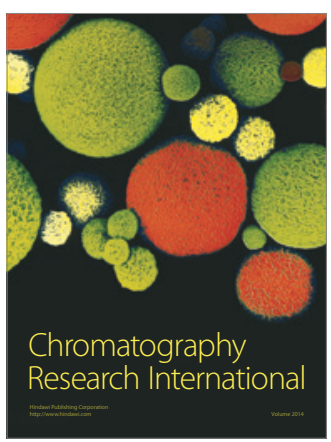

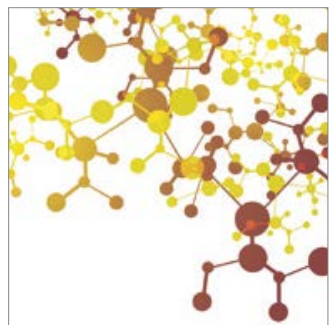

Applied Chemistry
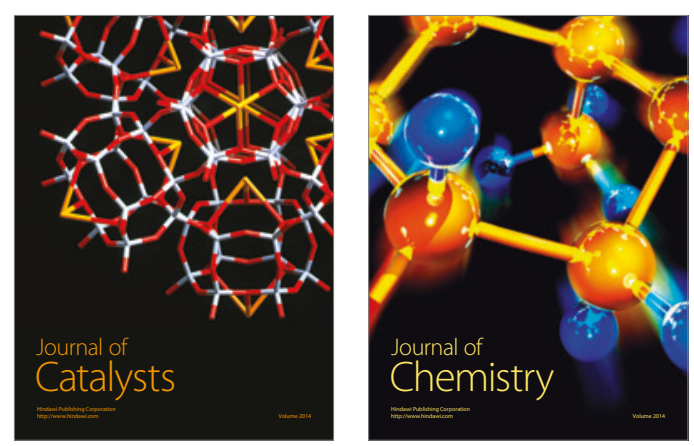
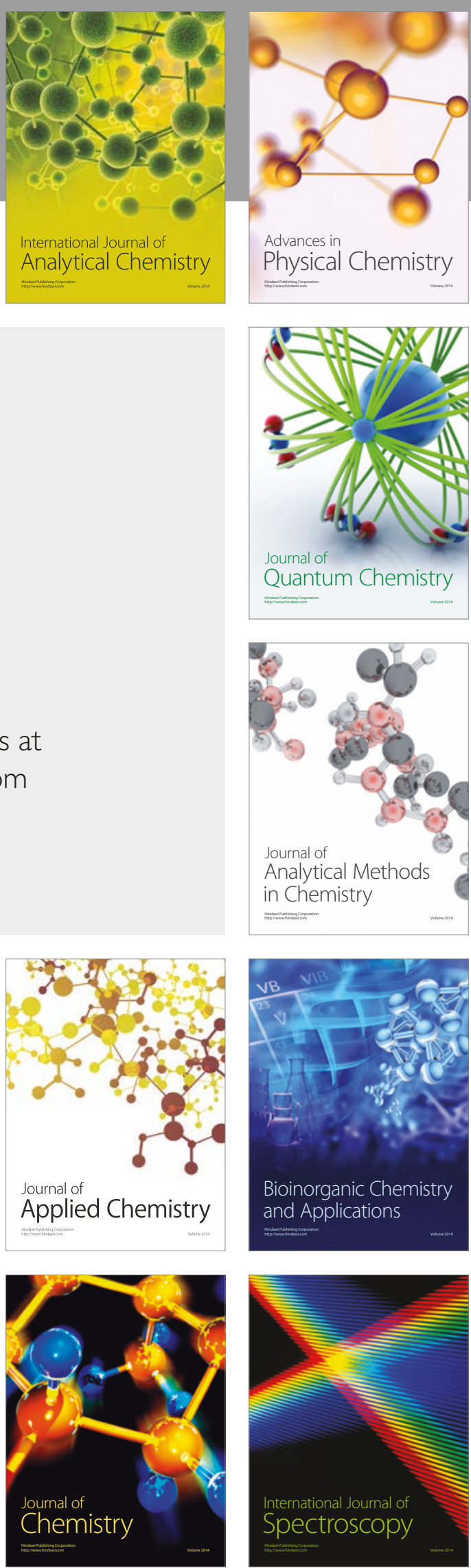